\title{
Mo-katkılı Mikroalg Kullanılarak Enerji Depolama Amaçlı Süperkapasitör Üretimi
}

\author{
Mustafa Kaya ${ }^{1}$, Fevzi Hansu², Murat Akdemir ${ }^{3 *}$ \\ ${ }^{1}$ Siirt Üniversitesi, Mühendislik Fakültesi, Kimya Mühendisliği Bölümü, Siirt, Türkiye, (ORCID: 0000-0002-0622-3163), mustafakaya@ @siirt.edu.tr \\ ${ }^{2}$ Siirt Üniversitesi, Mühendislik Fakültesi, Elektrik Elektronik Mühendisliği Bölümü, Siirt, Türkiye (ORCID: 0000-0002-5325-5459), f_hansu@ @iirt.edu.tr \\ 3* Siirt Üniversitesi, Mühendislik Fakültesi, Elektrik Elektronik Mühendisliği Bölümü, Siirt, Türkiye (ORCID: 0000-0001-9235-1913), muratakdemir@ siirt.edu.tr
}

(İlk Geliş Tarihi 14 Ekim 2021 ve Kabul Tarihi 6 Aralık 2021)

(DOI: 10.31590/ejosat.1009539)

ATIF/REFERENCE: Kaya, M., Hansu, F. \& Akdemir, M. (2021). Mo-katkılı Mikroalg Kullanılarak Enerji Depolama Amaçlı Süperkapasitör Üretimi. Avrupa Bilim ve Teknoloji Dergisi, (31), 493-497.

\section{$\ddot{O} \mathbf{z}$}

Enerji depolama ihtiyaçını gidermek ve geleneksel kondansatörler ve bataryaların dezavantajlarını aşmak için son zamanlarda süperkapasitörler üzerine yoğun çalışmalar yapılmaktadır. Bu çalışma kapsamında, tatlı su yosunu biyokütlesi olan Microcystis aeruginosa'ya Molibden katkılama yapılmış, karbonizasyon ve aktivasyon yöntemleri birleştirilerek aktif karbon üretimi gerçekleştirilmiştir. Üretilen aktif karbonlar püskürtme yöntemi kullanılarak elektrotlara dönüştürülmüş ve bir süperkapasitör hücresi hazırlanmıştır. Elektrotların elektrokimyasal testleri, elektrolit olarak $6 \mathrm{M} \mathrm{KOH}$ kullanılarak iki elektrotlu bir sistemle yapılmıştır. Elektrotunun spesifik kapasitans değeri $1 \mathrm{~A} / \mathrm{g}$ akım yoğunluğunda 9,84 F/g olarak hesaplanmıştır. Kararlılık testine tabi tutulan elektrotlarda sadece \%5,75 lik bir kapasite azalması görülmüştür. Elde edilen veriler 1şığında hazırlanan elektrotların ucuzluğu, düşük iç direnci ve kararlılığı nedeniyle enerji depolama alanında umut vaat ettiği düşünülmektedir.

\section{Production of a Supercapacitor for Energy Storage Using Mo-doped Microalgae}

\begin{abstract}
In order to meet the energy storage needs and overcome the disadvantages of conventional capacitors and batteries, intensive studies have been carried out on supercapacitors recently. In this study, Molybdenum was doped to Microcystis aeruginosa, a freshwater algae biomass, and activated carbon was produced by combining carbonization and activation methods. Produced activated carbons were converted into electrodes using sputtering method and a supercapacitor cell was prepared. Electrochemical tests of the electrodes were performed with a two-electrode system using $6 \mathrm{M} \mathrm{KOH}$ as the electrolyte. The specific capacitance value of the electrode was calculated as $9.84 \mathrm{~F} / \mathrm{g}$ at a current density of $1 \mathrm{~A} / \mathrm{g}$. The electrodes subjected to the stability test showed only a $5.75 \%$ capacitance reduction. In the light of the results, electrodes prepared are thought to be promising in the field of energy storage due to their cheapness, low internal resistance, and stability.
\end{abstract}

Keywords: Supercapacitor, Energy Storage, Activated Carbon, Biomass.

\footnotetext{
*Sorumlu Yazar: muratakdemir@siirt.edu.tr
} 


\section{Giriş}

Enerji depolama ihtiyaçını gidermek ve geleneksel kondansatörler ve bataryaların dezavantajlarını aşmak için son zamanlarda süperkapasitörler üzerine yoğun çalışmalar yapılmaktadır (Sakib et al., 2021; Tian et al., 2019). Süper kapasitörler, elektrikli çift katmanlı kapasitans (EDLC) ve psödokapasitans olmak üzere iki tür yük depolama mekanizmasına dayanır. EDLC mekanizmasında, elektrot ve elektrolitin sınır yüzeyinde çift bir yük tabakası oluşurken, psödokapasitif mekanizmada aktif malzeme bir faradaik redoks reaksiyonuna girer. Süper kapasitörler, yüksek güç yoğunluğu, mükemmel hız kapasitesi, uzun süreli ve kararlı çevrim ömrü gibi faydalı özelliklerinden dolayı elektronik iletişim, havacılık, elektrikli ulaşım vb. göze çarpan enerji depolama platformlarında kullanılmaktadırlar. Teorik olarak süper kapasitörler güvenilir enerji depolama sistemleri kaynağı olarak kanıtlanmış ve çeşitli uygulamalarda kullanılsa da, modern toplumun artan enerji talebini karşılamak için performanslarının hala daha fazla iyileştirilmesi gerekmektedir (Mohanty et al., 2021).

Elektrot malzemeleri süperkapasitör performansının belirlenmesinde en önemli rolü oynar. Süperkapasitörlerin elektrot malzemeleri genellikle karbon malzemeler, iletken polimerler ve metal oksitler/hidroksitlerden yapılmaktadır. Bunlar arasında, pil ve kapasitörlerin üretimi için en çok çalışılan ve uygulanan karbon bazlı malzemelerdir. Karbon bazlı malzemeler bol, düşük maliyetli, üretimi kolay, toksik olmayan, daha yüksek spesifik yüzey alanine sahip, iyi mekanik özellik, iyi elektronik iletkenlik, yüksek kimyasal kararlılık ve geniş çalışma sıcaklığı aralığı gibi birçok avantajlara sahiptirler (Pandolfo ve Hollenkamp, 2006; H. Wang ve Cui, 2019; Y. Wang et al., 2021). Literatürde karbon bazlı malzemeler kullanılarak birçok çalışma yapılmıştır. Bolat ve ark. (2021) tarafından yapılan bir çalışmada kalay katkılı mısır sapı Hidroklorik asit ile aktivasyon yapıldıktan sonra $45 \mathrm{dk} 450^{\circ}$ 'de yakılarak aktif karbon üretilmiştir. Üretilen aktif karbonlar kullanılarak tasarlanan iki elektrotlu süperkapasitör hücresi için elektrotların spesifik kapasitansları yaklaşık olarak 146,25 F/g olarak elde edilmiştir (Bolat et al., 2021). Yürüm (2019) ayçiçeği saplarından aktif karbon üretmek için fiziksel ve kimyasal aktivasyonun bir kombinasyonu kullanılmıştır. Üretilen elektrotların spesifik kapasitansı $0,05 \mathrm{~A} / \mathrm{g}$ akım yoğunluğunda 207 F/g olarak elde edilmiştir (Yürüm, 2019).

Selüloz, dünyada en bol bulunan yenilenebilir polimer ve biyokütle kaynağıdır. Bitkilerin ve alglerin hücre duvarlarının en önemli yapısal bileşenidir (Klemm et al., 2005). Molibden metali aktif karbonlara eklenerek malzemenin etkinliğini artırmak için kullanılmaktadır (Avci Hansu et al., 2020). Bu çalışma kapsamında, diğer çalışmalardan farklı olarak ilk kez Molibden katkılı Microcystis aeruginosa mikroalg biyokütlesi kullanılarak aktif karbon üretilmiş ve bu aktif karbon kullanılarak çevre dostu bir süper kapasitör hücre tasarlanmıştır. Süperkapasitörün kapasitansı ve kararlılığı elektrokimyasal yöntemler kullanılarak incelenmiştir.

\section{Materyal ve Metot}

Temizlenmiş ve kurutulmuş Microcystis aeruginosa, 24 saat boyunca $80{ }^{\circ} \mathrm{C}^{\prime}$ de $3 \mathrm{M} \mathrm{HC1}$ ile muamele edildi. Daha sonra saf su ile birlikte \%30 (ağırlıkça) $\mathrm{Mo}^{2+}(\mathrm{Na} 2 \mathrm{MoO} 4 \cdot 2 \mathrm{H} 2 \mathrm{O}$, Sigma
Aldrich 98\%) metali ilave edildi. Daha sonra bu numune 400 ${ }^{\circ} C^{\prime}$ de 45 dakika firında yakılarak aktivasyon ve karbonizasyon yoluyla aktif karbon elde edildi. Bu aktif karbon materyal, püskürtmeye uygun hale getirmek için bir havan kullanılarak ince bir şekilde öğ̈tüldü. Aktif karbon üzerine iletkenlik arttırıcı olarak nanotüp (\%10 ağırlıkça) ve bağlayıcı olarak poliviniliden florür (PVDF) (\%10 ağırlıkça) eklendi. Elde edilen karışım 10 dakika ultrasonik banyoda tutulduktan sonra manyetik karıştırıcıda 80 dakika karıştırıldı. Bulamaç daha sonra nikel köpügüun üzerine püskürtüldü. PVDF çözücüsü olarak kullanılan N-Metil-2-pirolidon'i uzaklaştırmak için nikel köpük firında 80 ${ }^{\circ} C^{\prime}$ de 24 saat bekletilmiştir. Anot ve katot hücreleri, firından çıkarılan nikel köpüğün eşit dairesel çaplarda kesilmesiyle hazırlanmıştır. Kağıt ayırıcı, her iki elektrot ve elektrolit çözeltisi olarak $6 \mathrm{M} \mathrm{KOH}$, iki elektrotlu hücre konfigürasyonunu oluşturmak için sızdırmaz bir alüminyum test aparatına yerleştirildi. Hücrenin elektrokimyasal karakterizasyonu, galvanostatik şarj deşarj (GŞD), döngüsel voltametri (CV) ve elektrokimyasal empedans spektroskopisi (EES) teknikleri kullanılarak oda sıcaklığında gerçekleştirildi.

\section{Araştırma Sonuçları ve Tartışma}

Molibden katkılı Microcystis aeruginosa kullanılarak hazırlanan aktif karbon kullanilarak 2 elektrotlu bir süperkapasitör tasarlanmıştır. Süperkapasitörün enerji depolama kapasitesi, kararlılığı ve enerji-güç yoğunluğu elektrtokimyasal karakterizasyon sonucu elde edilen CV eğrileri, empedans eğrileri ve şarj-deşarj eğrileri kullanılarak belirlenmiştir. Şekil 1a,b'de kapasitöre ait 5, 10, 20, 30, 40, 60, 80, and $100 \mathrm{mV} / \mathrm{s}$ tarama hızlarındaki $\mathrm{CV}$ eğrileri verilmiştir. Kapasitrün $\mathrm{CV}$ eğrileri ideal eğrilere benzemektedir. Tarama hızları arttıkça CV rğileri genişlemekte, fakat uç noktalarda sapmalar oluşmaktadır. $\mathrm{Bu}$ da elektrodun iç direncinden dolayı yüksek tarama hızlarında potansiyel düşümlerinin fazla olmasından kaynaklanmaktadır. Kullanılan aktif malzeme malzemede herhangi bir metal oksit veya polimer bazlı malzeme olmadığı için redox sapmaları oluşmamış ve tipik bir elektrik çift tabaka kapasitör özelliği sergilemiştir. 

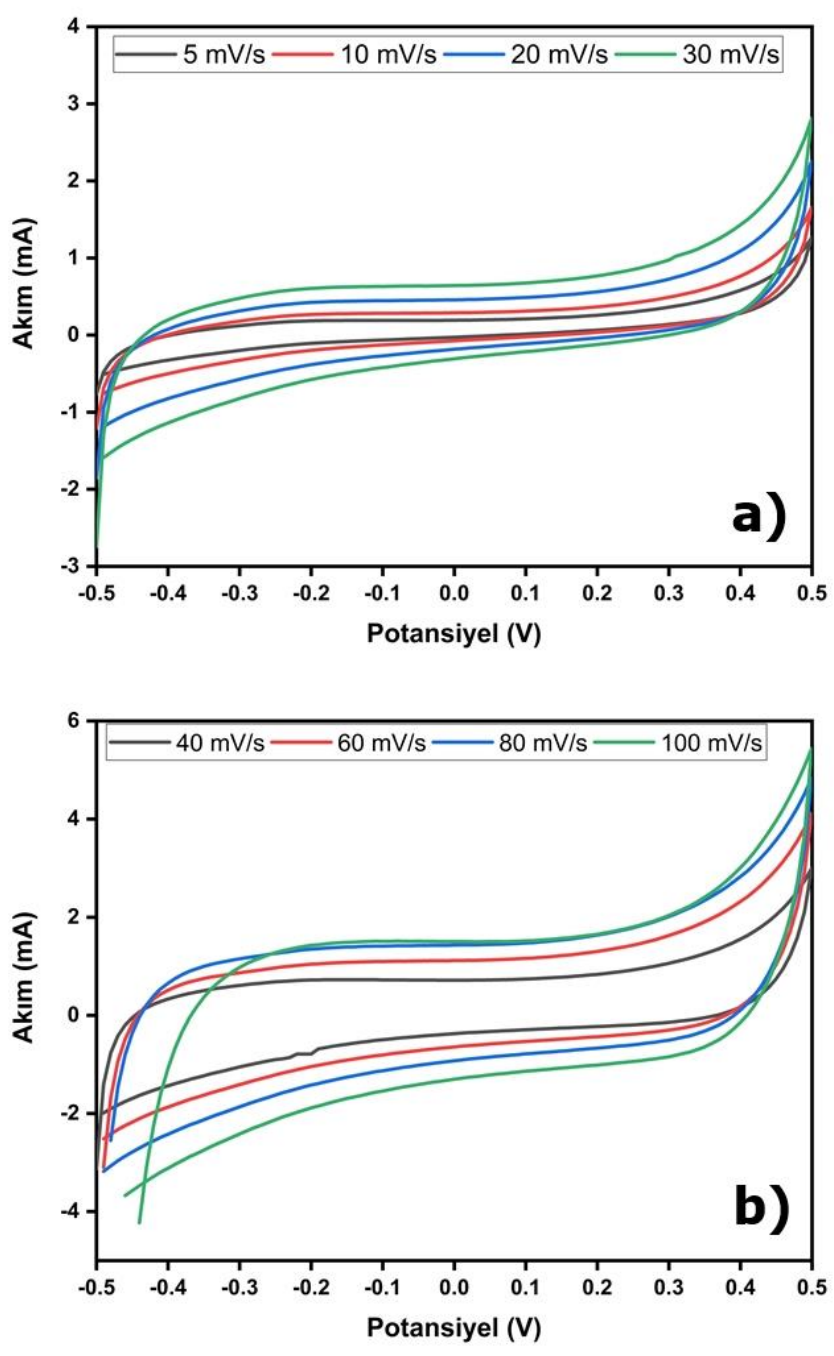

Şekil 1. Süperkapasitör hücresine ait farklı tarama hızlarındaki

CV eğrileri

Elektrotların EIS analizi, $10 \mathrm{mV}$ genlik ile $5 \mathrm{~Hz}$ ile $30 \mathrm{kHz}$ frekans aralığında gerçekleştirildi ve Şekil 2'de verildi. Süperkapasitörün eşdeğer seri direnci $\mathrm{R}_{\mathrm{S}}$ yaklaşık $0.62 \Omega$ olarak ölçülmüştür. $R_{S}$ direnci çok düşüktür ve bu düşük direnç değeri süperkapasitörün güç aktarımının yüksek seviyelerde yapılabilmesini destekler (Cheng et al., 2011; Yan et al., 2014). Orta frekans aralığındaki yarım daire çapı, arayüzey yük transfer direncini $\left(R_{c t}\right)$ değerlendirmek için kullanılır. Üretilen super kapasitörün $\mathrm{R}_{\mathrm{ct}}$ direnci $1.24 \Omega$ olarak hesaplanmıştır ve üstün bir yük transfer yeteneğine sahip olduğunu göstermektedir (Zhu et al., 2018). Düşük frekanslarda, empedans eğrilerinin eğimi, elektrolit ile elektrot malzemesi arasındaki difüzyon direncinin olduğunu gösterir. Elektrotlar için eğim $72^{\circ}$ olarak hesaplanmıştır ve bu değer elektrot malzemesinin elektrolit ile iyi bir etkileşime geçtiğini ve difüzyon direncinin düşük olduğunu göstermektedir (Gamby et al., 2001; Zhu et al., 2018).

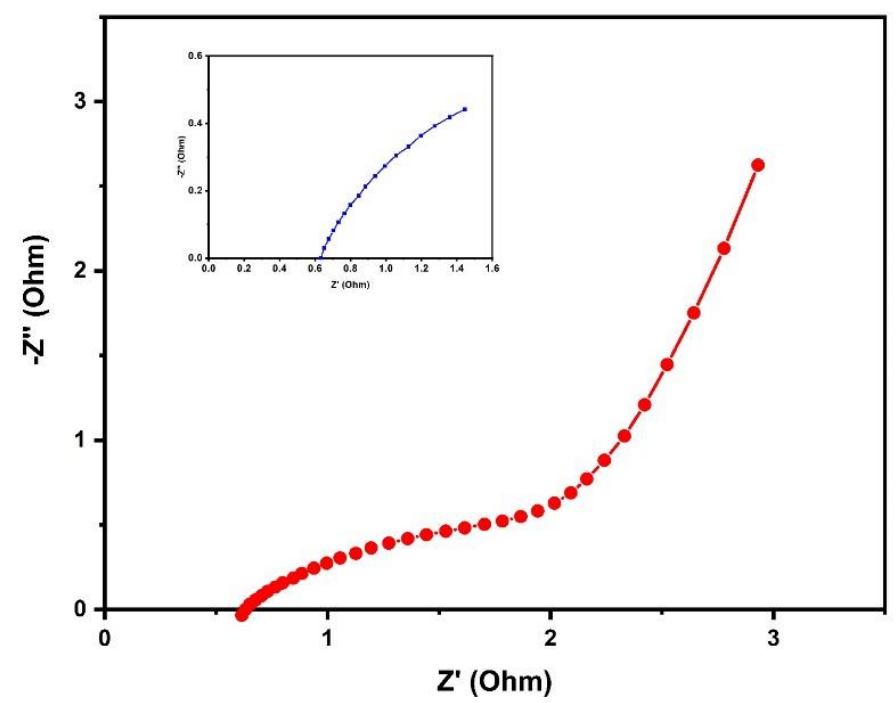

Şekil 2. Hazırlanan süperkapasitöre ait empedans eğrisi

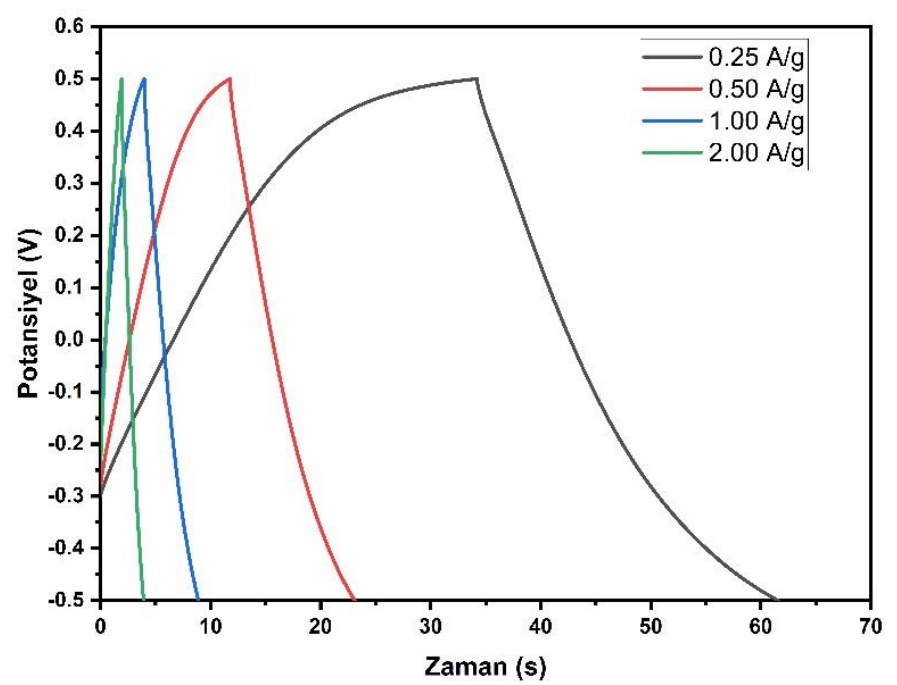

Şekil 3. Süperkapasitör hücresine ait farklı akım yoğunluklarındaki şar-deşarj eğrileri

Hazırlanan elektrotların şarj-deşarj eğrileri galvanostatik şarj deşarj tekniği kullanılarak elde edilmiştir. Hücreye ait farklı akım yoğunluklarındaki şarj-deşarj eğrileri Şekil 3'de verilmiştir. Şarj-deşarj eğrileri ideal süperkapasitör eğrileriyle benzerlik göstermektedir. Eğrilerin mükemmelliği, elektrot yüzeyleri ile elektrolit sıvısı arasındaki iyon değişiminin hızlı ve tersinir bir şekilde gerçekleştiğini göstermektedir. Deşarj işleminin başlangıcında $0,25 \mathrm{~A} / \mathrm{g}^{\prime} \mathrm{da}$ yaklaşık $6 \mathrm{mV}, 0,5 \mathrm{~A} / \mathrm{g}$ 'da yaklaşı 12 $\mathrm{mV}, 1 \mathrm{~A} / \mathrm{g}^{\prime}$ da $24 \mathrm{mV}$ ve $2 \mathrm{~A} / \mathrm{g}^{\prime}$ da yaklaşık $44 \mathrm{mV}$ IR düşüşü gözlemlenmiştir. Bu değerler hazırlanan elektrot malzemelerinin iç direncinin düşük olduğunu kanıtlamaktadır (Song et al., 2019). Elektrotların spesifik kapasitansı şarj-deşarj eğrileri kullanılarak Denklem 1 aracılığıyla hesaplanmıştır:

$C=\frac{2 \cdot I \cdot \Delta t}{m \cdot \Delta V}$

Burada I, akımı (A); $\Delta \mathrm{t}$, deşarj süresini (s); $\Delta \mathrm{V}$, uygulanan gerilim aralığını (V); m, bir elektrot üzerindeki aktif madde miktarını (g) belirtmektedir. Kapasitans değerleri 0,25 A/g için $13,68 \mathrm{~F} / \mathrm{g}, 0,50 \mathrm{~A} / \mathrm{g}$ için $11,34 \mathrm{~F} / \mathrm{g}, 1,00 \mathrm{~A} / \mathrm{g}$ için $9,84 \mathrm{~F} / \mathrm{g}$ ve 2,00 $\mathrm{A} / \mathrm{g}$ için $8,04 \mathrm{~F} / \mathrm{g}$ olarak hesaplanmıştır. Elektrotların kararlılığını belirlemek için $1 \mathrm{~A} / \mathrm{g}$ akım yoğunluğunda 100 döngülük şarj-deşarj analizi yapılmıştır ve sonuçlar Şekil 4'te verilmiştir. 100 döngü sonucunda elektrotlar ilk kapasitelerinin 
\%94,25'ünü halen sürdürmektedirler. $\mathrm{Bu}$ da üretilen elektrot malzemelerinin kararlı bir yapıya sahip olduğunu göstermektedir.

Elektrotların kapasitans değerleri esas olarak kullanılan biyokütle malzemesinin tipine, biyokütlenin yakıldığı sıcaklığa, hazırlama yöntemine, aktivasyon maddesine, katkı maddesine ve kullanılan elektrolit tipine bağlıdır. Hazırlanan elektrotların kapasitans değeri, litaratüde çay atı̆̆ (Özarslan et al., 2021), pirinç kabuğu (W. Zhang et al., 2017), Spirulina platensis (Elma Karakaş et al., 2021), limon kabuğu (Mehare et al., 2021), kahve telvesi atığg1 (Akdemir et al., 2021), nilüfer kökü (Y. Zhang et al., 2017), fistic kepeği (Kang et al., 2018), Ceviz kabuğu (Lan et al., 2020), and lif kabağı süngeri (Luan et al., 2016) kullanılarak elde edilen aktif karbonlar kullanılarak hazırlanan elektrotların kapasitans değerlerine yakın değerler elde edilmiştir. Elde edilen sonuçlar 1şı̆̆ında Molibden katkılı Microcystis aeruginosa kullanılarak hazırlanan elektrotların Mangan katkılı Microcystis aeruginosa kullanilarak hazırlanan elektrotlardan (Inal et al., 2021) daha düşük bir enerji depolama kapasitesine sahip iken kapsitans sürdürme açısından daha kararlı bir yapıya sahip olduğu görülmüştür.

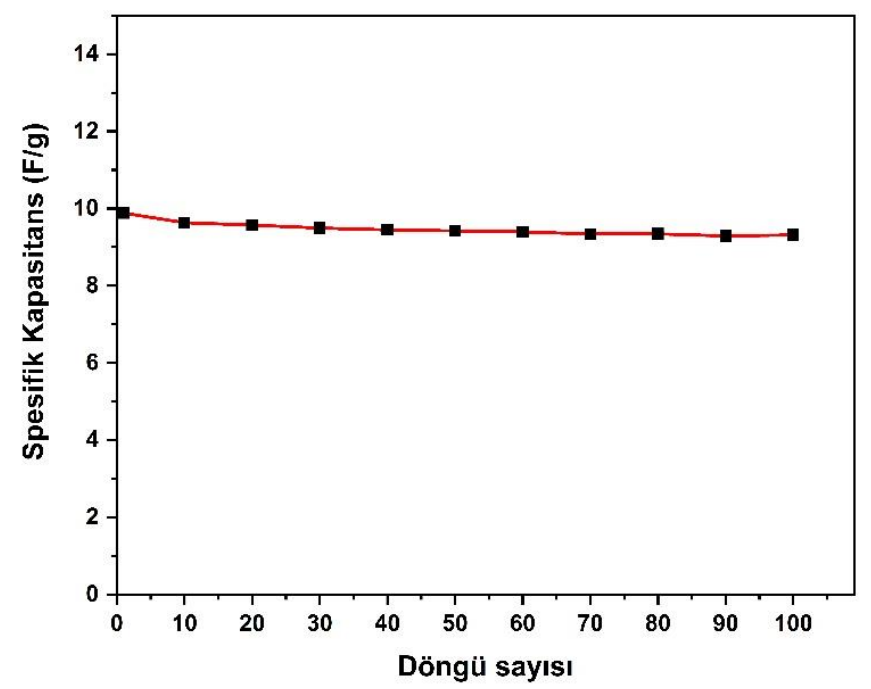

Şekil 4. Süperkapasitör hücresine ait 100 döngülük şarj-deşarj sonrası kapasitans azalması

\section{Sonuç}

$\mathrm{Bu}$ çalışma kapsamında, tatlı su yosunu biyokütlesi olan Microcystis aeruginosa'ya Molibden katkılama yapılmış, karbonizasyon ve aktivasyon yöntemleri birleştirilerek aktif karbon üretimi gerçekleştirilmiştir. Üretilen aktif karbonlar püskürtme yöntemi kullanılarak elektrotlara dönüştürülmüş ve bir süperkapasitör hücresi hazırlanmıştır. Elektrotların elektrokimyasal testleri, elektrolit olarak $6 \mathrm{M} \mathrm{KOH}$ kullanılarak iki elektrotlu bir sistemle yapılmıştır. Elektrotunun spesifik kapasitans değeri $1 \mathrm{~A} / \mathrm{g}$ akım yoğunluğunda 9,84 F/g olarak hesaplanmıştır. Kararlılık testine tabi tutulan elektrotlarda sadece $\% 5,75$ lik bir kapasite azalması görülmüştür. Mangan katkılamanın Molibten katkılamaya göre kapasitans artırımı üzerinde daha etkili olduğu görülmüştür. Elde edilen veriler 1şığında hazırlanan elektrotların ucuzluğu, düşük iç direnci ve kararlılığı nedeniyle enerji depolama alanında umut vaat ettiği düşünülmektedir. Ayrıca farklı aktivasyon yöntemleri ve farklı yakma sıcaklıkları kullanılarak daha büyük kapasiteli elektrotların geliştirilebileceği düşünülmektedir.

\section{Teşekkür}

$\mathrm{Bu}$ çalışma Siirt Üniversitesi Bilimsel Araştırma Projeleri Koordinatörlüğü tarafindan 2020-Sï̈MÜH-014 nolu proje ile desteklenmiştir. Siirt Üniversitesi Biyoteknoloji Laboratuvarına değerli katkılarından ve Siirt Üniversitesi Bilimsel Araştırma Projeleri Koordinatörlüğüne mali katkılarından dolayı teşekkür ederiz.

\section{Kaynakça}

Akdemir, M., Avci Hansu, T., Caglar, A., Kaya, M., \& Demir Kivrak, H. (2021). Ruthenium modified defatted spent coffee catalysts for supercapacitor and methanolysis application. Energy Storage, 3(4), e243. doi:https://doi.org/10.1002/est2.243

Avci Hansu, T., Sahin, O., Caglar, A., \& Kivrak, H. (2020). A remarkable Mo doped $\mathrm{Ru}$ catalyst for hydrogen generation from sodium borohydride: the effect of Mo addition and estimation of kinetic parameters. Reaction Kinetics, Mechanisms and Catalysis, 131(2), 661-676. doi:10.1007/s11144-020-01884-8

Bolat, M., Yavuz, C., \& Kaya, M. (2021). Investigation of dualfunctionalized novel carbon supported $\mathrm{Sn}$ material from corn stalk for energy storage and fuel cell systems on distributed generations. Journal of Materials Science: Materials in Electronics, 32(13), 18123-18137. doi:10.1007/s10854-021-06356-w

Cheng, Q., Tang, J., Ma, J., Zhang, H., Shinya, N., \& Qin, L.-C. (2011). Graphene and nanostructured $\mathrm{MnO} 2$ composite electrodes for supercapacitors. Carbon, 49(9), 2917-2925.

Elma Karakaş, D., Akdemir, M., Atabani, A. E., \& Kaya, M. (2021). A dual functional material: Spirulina Platensis waste-supported $\mathrm{Pd}-\mathrm{Co}$ catalyst as a novel promising supercapacitor electrode. Fuel, 304, 121334. doi:https://doi.org/10.1016/i.fuel.2021.121334

Gamby, J., Taberna, P., Simon, P., Fauvarque, J., \& Chesneau, M. (2001). Studies and characterisations of various activated carbons used for carbon/carbon supercapacitors. Journal of Power Sources, 101(1), 109-116.

Inal, I. I. G., Akdemir, M., \& Kaya, M. (2021). Microcystis aeruginosa supported-Mn catalyst as a new promising supercapacitor electrode: A dual functional material. International Journal of Hydrogen Energy, 46, 2153421541.

Kang, W., Lin, B., Huang, G., Zhang, C., Yao, Y., Hou, W., . . . Xing, B. (2018). Peanut bran derived hierarchical porous carbon for supercapacitor. Journal of Materials Science: Materials in Electronics, 29(8), 6361-6368.

Klemm, D., Heublein, B., Fink, H. P., \& Bohn, A. (2005). Cellulose: fascinating biopolymer and sustainable raw material. Angewandte chemie international edition, 44(22), 3358-3393.

Lan, D., Chen, M., Liu, Y., Liang, Q., Tu, W., Chen, Y., ... Qiu, F. (2020). Preparation and characterization of high valueadded activated carbon derived from biowaste walnut shell by $\mathrm{KOH}$ activation for supercapacitor electrode. Journal of Materials Science: Materials in Electronics, 31(21), 1854118553.

Luan, Y., Huang, Y., Wang, L., Li, M., Wang, R., \& Jiang, B. (2016). Porous carbon@ MnO2 and nitrogen-doped porous carbon from carbonized loofah sponge for asymmetric 
supercapacitor with high energy and power density. Journal of Electroanalytical Chemistry, 763, 90-96.

Mehare, M., Deshmukh, A., \& Dhoble, S. (2021). Bio-waste lemon peel derived carbon based electrode in perspect of supercapacitor. Journal of Materials Science: Materials in Electronics, 32(10), 14057-14071.

Mohanty, A., Jaihindh, D., Fu, Y.-P., Senanayak, S. P., Mende, L. S., \& Ramadoss, A. (2021). An extensive review on three dimension architectural Metal-Organic Frameworks towards supercapacitor application. Journal of Power Sources, 488, 229444.

Özarslan, S., Raşit Atelge, M., Kaya, M., \& Ünalan, S. (2021). A Novel Tea factory waste metal-free catalyst as promising supercapacitor electrode for hydrogen production and energy storage: A dual functional material. Fuel, 305, 121578. doi:https://doi.org/10.1016/j.fuel.2021.121578

Pandolfo, A. G., \& Hollenkamp, A. F. (2006). Carbon properties and their role in supercapacitors. Journal of Power Sources, 157(1), 11-27. doi:https://doi.org/10.1016/j.jpowsour.2006.02.065

Sakib, M. N., Ahmed, S., Rahat, S. M. S. M., \& Shuchi, S. B. (2021). A review of recent advances in manganese-based supercapacitors. Journal of Energy Storage, 44, 103322. doi:https://doi.org/10.1016/j.est.2021.103322

Song, X., Ma, X., Li, Y., Ding, L., \& Jiang, R. (2019). Tea waste derived microporous active carbon with enhanced doublelayer supercapacitor behaviors. Applied Surface Science, 487, 189-197.

Tian, Y., Yang, X., Nautiyal, A., Zheng, Y., Guo, Q., Luo, J., \& Zhang, X. (2019). One-step microwave synthesis of MoS 2/MoO3@ graphite nanocomposite as an excellent electrode material for supercapacitors. Advanced Composites and Hybrid Materials, 2(1), 151-161.

Wang, H., \& Cui, Y. (2019). Nanodiamonds for energy. Carbon Energy, 1(1), 13-18.

Wang, Y., Zhang, L., Hou, H., Xu, W., Duan, G., He, S., . . Jiang, S. (2021). Recent progress in carbon-based materials for supercapacitor electrodes: a review. Journal of Materials Science, 56(1), 173-200.

Yan, X., Yu, Y., \& Yang, X. (2014). Effects of electrolytes on the capacitive behavior of nitrogen/phosphorus co-doped nonporous carbon nanofibers: an insight into the role of phosphorus groups. RSC Advances, 4(48), 24986-24990.

Yürüm, A. (2019). Sunflower stalk based activated carbon for supercapacitors. Hacettepe Journal of Biology and Chemistry, 47(3), 235-247.

Zhang, W., Lin, N., Liu, D., Xu, J., Sha, J., Yin, J., . . Lin, H. (2017). Direct carbonization of rice husk to prepare porous carbon for supercapacitor applications. Energy, 128, 618625.

Zhang, Y., Liu, S., Zheng, X., Wang, X., Xu, Y., Tang, H., . . Luo, J. (2017). Biomass organs control the porosity of their pyrolyzed carbon. Advanced functional materials, 27(3), 1604687.

Zhu, X., Yu, S., Xu, K., Zhang, Y., Zhang, L., Lou, G., . . Shen, Z. (2018). Sustainable activated carbons from dead ginkgo leaves for supercapacitor electrode active materials. Chemical Engineering Science, 181, 36-45. 